\section{PETERSFIELD COTTAGE HOSPITAL.}

CASE OF POPLITEAL ANEURISM; FAILURE OF COMPRESSION; ESMARCH'S BANDAGE $\Lambda N D$ GENUFLEXION; LIGATURE OF FEMORAL ARTERY; RECOVERY.

(Under the care of Dr. A. W. LEAchmaN.)

G. A—, aged thirty-eight, a farm labourer, was admitted on June 3rd, 1882, complaining of pain in the left leg and a swelling behind the knee. His family history was good; he had enjoyed excellent health, had never had syphilis, gout, or rheumatism, but had drank beer freely. Nine or ten weeks ago he was helping to lift a cart wheel out of a rut, when he felt a sudden pain in the calf of the left leg. This passed off in a few days, but two or three weeks afterwards he noticed a swelling behind the left knee which gradually increased in size, and ten days before his admission he was obliged to give up work on account of the pain and swelling of the limb.

On admission a tumour, about the size of a hen's egg, was felt in the left popliteal space with very visible pulsation, and communicating to the hand a rasping thrill. With the stethoscope a rough systolic bruit was heard. The veins over the tumour were swollen, and the leg and foot oedematous. The leg could not be completely flexed or extended. The posterior tibial artery could not be felt at the ankle Compression of the femoral artery at Poupart's ligament stopped the pulsation in the tumour. The circumference of the sound limb at the knee was $13 \frac{1}{2}$ inches, of the affected leg 15 inches. The patient had great pain in the knee, had little appetite, and slept badly. The urine was free from albumen. Perfect rest in bed was enjoined, and iodide of potassium in ten-grain doses three times a day, and a diet limited to twelve ounces of solid and halt a pint of liquid daily were ordered.

June 18th.-An attempt at genuflexion causing such tension in the aneurism as to threaten rupture, compression of the femoral artery in Scarpa's triangle was kept up by Signoroni's tourniquet and by the fingers alternately for ten hours. The pain caused by this treatment was so severe that chloroform was administered during the last two hours and a half. On discontinuing pressure pulsation returned in the aneurism but in a less degree' Next day Esmarch's bandage was applied tightly from the toes to the lower border of the aneurism, then across the patella to its upper border, whence it was carried for a distance of two-thirds of the length of the thigh, the elastic ligature was then tightly fixed round the thigh, and the bandage removed, the limb being enveloped in cotton-wool and flannel. The ligature was kept on for two hours and a quarter, the patient being under chloroform. Before removing the ligature a compressor was applied to the femoral above it with a few read. justments (during which digital compression was kept up) and retiined there for seven hours. On removing the tourniquet pulsation returned in the tumour, which, however, was smaller, felt more solid, and on auscultation commuuicated a les rough bruit to the eir. After this date compression was kept up by the patient himself. This was effected either by a (5 lb.) shot bag, by Signoroni's tourniquet, or by the fingers, the methods being varied according to the parient's inclination. After a week of this treatment the aneurism hecame smaller and more solid and its impulse less heaving. The odema of the leg subsided and the patient was free from pain. Cumpression was now supplemented by genuflexion at night, the leg being now capable of being bent to such an angle as to arrest pulsation in the tumour.

On Sept. 25 rh the aneurism seemed almost cured, pulsation being at times scarcely perceptible. The collateral cir culation was well established. The articular arteries could be distinctly felt pulsating.

On Nov. 17th, on conrultation with Messrs. Cross and Ticehnrst, it was decided to tie the artery, prolonged compression having failed to effect, a cure. This Dr. Leachman did on the $20 \mathrm{~h}$. The patient being under ether the femoral was tied at the apex of Scarpa's triangle with carbolised catgut, the wound sponged with carbolic lotion, and the edges brought together with silver wire sutures. No other antiseptic precautions were adopted. After the operation the temperature rose above the normal on one occasion only otherwise it remained subnormal for some days. Slight pulsation was felt in the aneurism on the $25 \mathrm{~h}$; but it gradually censed, and on the 30 th the wound was healed without any previous suppuration.
On Jan. 8th, 1883, the patient was discharged well, and went to work.

Remarks by Dr. LEACHMAN. - In this case compression was continued for an unusually long period. Successful cases of even more lengthened compression (eight months), quoted by Holmes, seemed, however, to warrant a prolonged trial of this treatment before subjecting the patient to the risks of Hunter's operation; and I believe that the long. continued compression, by giving time for the thorough establishment of the collateral circulation, reduced to a minimum the principal danger of the operation-gangrene, The rapid healing of the wound without suppuration in the absence of antiseptic precautions is also noteworthy.

\section{A}

\section{ROYAL MEDICAL \& CHIRURGICAL SOCIETY.}

Case in which Cysts in connexion with both Kidneys were opened and drained, and a Tumour of the Ovary removed. - Nephrectomy for Rupture of the Kidney followed by Cystotomy for relief of Cystitis.-Excision of an Enlarged Cancerous Kidney. - Hamatoma of Kidney.

THE ordinary meeting of this Society was held on the 22nd inst., Professor J. Marshall, President, in the chair. Four interesting communications, all dealing with renal surgery, were re $x d$, the authors baing Mr. K. Thornton, $\mathrm{Dr}$ Riwdon, of Liverpool, SirSpencer Wells, and the President; and the discussion upon them was mainly occupied with the choice of the kind of operation in excision of the kidney, the propriety of excision in malignant disease and some details in the after-treatment of these cases. The following are abstracts of the four papers read :-

A Case in which Cysts in connexion with both Kidneys were opened and drained, and a Tumour of the Right Ovary removed, the patient remaining in good health, by Mr. KNowsley ThorntoN. E. M-, a single woman, aged twenty - seven, was armitted into the Samaritan Hospital in November, 1877, under the care of Mr. Spencer Wells. She had had a child born alive at full term when she was only fifteen. When seventeen she had inflammation of both kidneys, and from that time had been failing in health, and had been unable to lie on her right side for fully a year. When admitted she had a fluctuant tumour of considerable size in the right side of the abdomen, with a red, tender, and pointing swelliag in the right loin behind this tumour. There was a smaller tumour in the left side of the abdomen, which occupied an exactly similar position to that in the right side, but did not distinctly fluctuate. There was nothing wrong with the urine, and no trouble with bladder or kidneys, except pain across the loins and in the lower abdomen, which was not, however, constant. Menstruation was regular. The swelling in the right loin was freely incised by Mr. Wells under Listerian management, but nothing to account for its presence was found, and no communication appeared to exist between it and the kidney or ureter. It contained fluid very like that from an ovarian cyst, with an immense quantity of cholesterine. It was dressed antiseptically and drained, and in six weeks the patient went home well, all trace of the cyst having disappeared. Six or eight weeks afterwards she had an attack of gout in both feet, then the wound opened and a large discharge of fluid with much cholesterine took place, and the wound gradually healed up again. In January, 1880, she was readmitted uncier the author's care, with a tumour of the right ovary, for which he performed ovariotomy. While the abdomen was open he examined the kidneys and ureters. The right kidney was large and sacculated and its ureter was much enlarged, especially at the pelvic brim. The left kidney and ureter appeared quite normal. The recovery after the ovariotomy was rapid; but soon after getting up the swelling in the right loin reappeared with fever, \&c., and she was obligel t) return to bed. It was poulticed antisentically until it broke, and then drained as before, and she left the hospital apparently well in three weeks from the time it burst, and about six weeks from the ovariotomy. In six weeks she returned with a swelling in the left iliac region 